\title{
Promoting the Computational Science Initiative (ProCSI)
}

\author{
Dan Melanz \\ University of Wisconsin - Madison
}

\begin{abstract}
PROmoting the Computational Science Initiative (ProCSI) Summer Program is a six day precollege engineering program for high school students who come from ethnic groups that are traditionally underrepresented in engineering. The ProCSI program is designed to attract outstanding high school students to the College of Engineering at UW Madison. Students become part of a pre-collegiate community that will explore the excitement and rigors of engineering and collegiate life through participation in hands-on labs, industry and undergraduate seminars, graduate research presentations, college preparation workshop, lab tours, undergraduate admissions presentations, and social activities. Students will go through a lab sequence focused on Mechanical Engineering, Applied Mathematics, Computer Science, Computational Science, and Engineering Applications, respectively.
\end{abstract}

\section{Sponsoring Organization Information}

The sponsoring organization is the Simulation Based Engineering Laboratory (SBEL). Broadly speaking, the goals of this lab are (1) to investigate and develop computational tools and methods that help one understand how systems change in time, and (2) to use these tools and methods to gain insights into the dynamics of processes. Most of our effort is dedicated to understanding through simulation the time evolution of mechanical systems, a topic sometimes called multibody dynamics simulation. The primary focus of the lab is the simulation of classical multibody dynamics at macro and meso-scales. The idea here is to produce numerical algorithms that are capable of robustly and efficiently predicting the time evolution of a collection of mutually interacting elements, which can be rigid or flexible. The primary motivation underlying our research efforts is the simulation-based engineering concept, whose entire goal is that of replacing, whenever possible, hardware prototyping with virtual prototyping in design engineering. In a wider context, as members of the Computational Science community, we promote the idea of scientific discovery through advanced computing.

An important part of our mission in the Simulation Based Engineering Lab is to let other people learn about the potential of simulation, in particular, and Computational Science, in general. We believe strongly that there is a lot of merit in exposing to this emerging discipline groups of people that in their day-to-day life are very unlikely to get the chance to understand and see how computers are used in Science and Engineering. Belonging to a public education institution, we do this not only because we ought to, but because we truly believe that a career in Computational Science is an exciting and rewarding path to take at this time. 


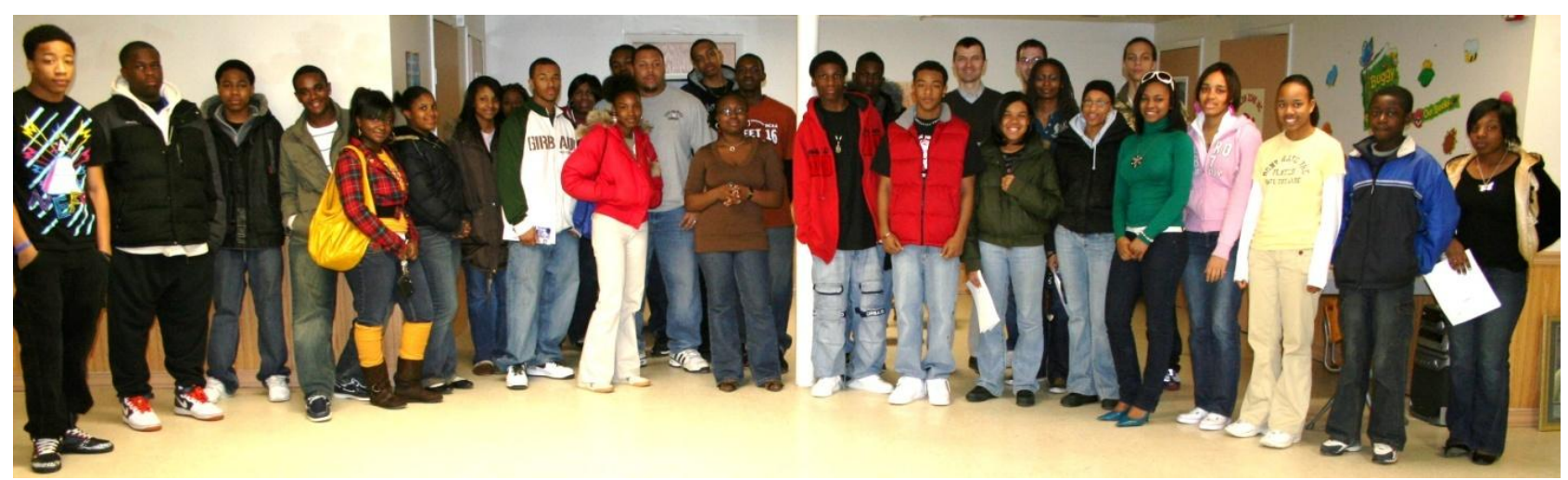

Figure 1. ProCSI 2008 recruiting, Milwaukee: African-American high school students of the Dream-Chasing nonprofit organization, lab graduate students Yakira Braden and Justin Madsen, and PI Dan Negrut.

PROmoting the Computational Science Initiative (ProCSI) Summer Program is a six day precollege engineering program for high school students who come from ethnic groups that are traditionally underrepresented in engineering. The ProCSI program is organized by the Simulation Based Engineering Lab in the Department of Mechanical Engineering with financial support from the National Science Foundation, and it is designed to attract outstanding high school students to the College of Engineering at UW Madison. Students become part of a precollegiate community that will explore the excitement and rigors of engineering and collegiate life through participation in hands-on labs, industry and undergraduate seminars, graduate research presentations, college preparation workshop, lab tours, undergraduate admissions presentations, and social activities. Students will go through a lab sequence focused on Mechanical Engineering, Applied Mathematics, Computer Science, Computational Science, and Engineering Applications, respectively.

\section{Previous Funding}

Partial ProCSI funding for 2008 was secured through NSF project CMMI-0700191, and for 2009 to 2013 through NSF project CMMI-0840442. Additional funding was provided by an industry partner (BAE Systems).

\section{Participants Anticipated}

The ProCSI Engineering Summer Camp has been host to several minority high-school students of African American, Hispanic, and Hmong descent from Wisconsin and Illinois. During ProCSI 2008, 13 African American High School Students from Milwaukee, WI participated. Of these 13 students, 5 were female. During ProCSI 2009, 9 students from varying ethnic backgrounds participated from both Wisconsin and Illinois. Of these 9 students, 2 were female. During ProCSI 2010, 14 students (4 female), also from varying ethnic backgrounds participated. It is expected that ProCSI 2011 will be composed of participants from similar underrepresented minority backgrounds. Attendance will be increased to 16 students total, with approximately a third of the group being female. ProCSI targets high school students finishing the $9^{\text {th }}$ or $10^{\text {th }}$ grade. This decision was reached after consultation with the Diversity Affairs Office (DOA) of the College of Engineering. Students are encouraged to apply if they are going into their junior or senior year of high school with selection being based on grade point average, transcripts, and recommendations. 


\section{Metrics}

In terms of impact assessment, the web-based Student Assessment of Learning Gains Instrument (SALGI), developed by the National Institute for Science Education (NISE) College Level One Team under NSF support at the University of Wisconsin, will be used for outcome control and implementation of a continuous improvement process, which also draws on exit interviews with the participants. A list of ProCSI alumni is available

http://sbel.wisc.edu/Outreach/ProCSI/ ProCSIalumni.htm. All 2008 ProCSI alumni went on to college in Fall 2009 at University of WisconsinMadison, University of WisconsinMilwaukee, DePaul, Southern Illinois University-Edwardsville, and Howard University.

\section{Ability to sustain and replicate}

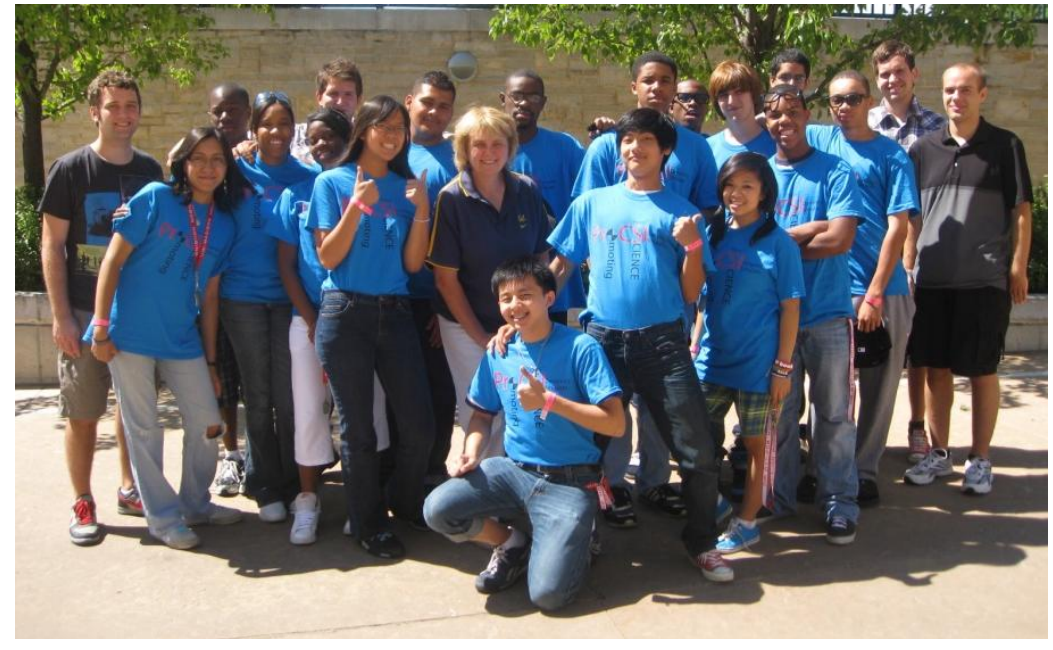

Figure 2. Students from ProCSI 2010.

There are several requirements to fulfill in order to replicate this program. First of all, it is crucial to recruit students that want to learn about Computational Science. It is important that the students have a place to sleep during their stay. Transportation, food, and classrooms are also necessities to this program. Arguably the most important piece to ProCSI is providing the students with useful information about mechanical engineering, mathematics, and computer science and ensuring that the lecturers are knowledgeable about the topic that they are presenting. Based on the successful implementation of ProCSI 2008 and 2009, there is no doubt that this program can be sustained.

Assisting in the effort to sustain ProCSI is a similar program offered by the UW-Madison campus, called the Engineering Summer Program (ESP). ESP is a six-week residential program designed to attract future engineers to the University of Wisconsin-Madison College of Engineering. It has, on average, 20 participants each summer, 92 percent of whom represent underrepresented ethnic minority backgrounds. In recent years, ESP participants have made up 23 percent of all targeted underrepresented students graduating from UW-Madison with engineering degrees. The vision is for ProCSI to serve as a preamble to ESP for students entering the $11^{\text {th }}$ and $12^{\text {th }}$ grades. ProCSI and ESP thus cover the entire high school student population with interest in Math and Science; i.e., the likely candidates for future careers in Engineering.

\section{Budget}

In conjunction with increasing the participation in the ProCSI programs by adding six additional highschool students, the PI requests $\$ 3,000$ for each of the three years of the project. This will cover the following expenses:

- ProCSI Housing; $\$ 45 /$ night for each of the six students in double occupancy rooms, for a total of $\$ 1,350$.

- ProCSI Meals; breakfast $\$ 8$, lunch $\$ 9$, dinner $\$ 13$ for six students: $\$ 900$.

- ProCSI Transportation; to/from Milwaukee, and local transportation. 


\section{Project Description/Overview}

The ProCSI program (from Promoting the Computational Science Initiative, pronounced like "proxy"), introduces students to Computational Science through the use of examples drawing on physics-based models for computer games and virtual prototyping in ADAMS. The 2008 and 2009 ProCSI schedules are available along with more than 200 pictures at http://sbel.wisc.edu/. The participating minority high-school students (African American, Hispanics, and Hmong from Wisconsin and Illinois) are recruited through seminars given by lab members in Milwaukee and with assistance from the Diversity Affairs Office (DOA) of the College of Engineering (letter included from DAO Assistant Dean). The instructional segment of the program runs for approximately five hours daily with modules covering, in this order, Mechanical Engineering,

\section{DISCUSSION}

\section{HANDS-ON}

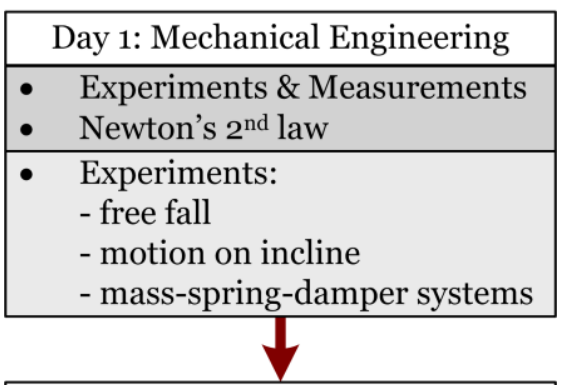

Day 2: Applied Mathematics

- Equations governing free fall and motion on incline

- Rate of change and Euler formula for handling equations with rate of change

- ADAMS simulation:

- free fall

- motion on incline

- mass-spring-damper system

Day 3: Computer Science

- Computer Architecture

- Fast computers: Flop rates

- Computer Graphics: Pov-RAY

- Pov-RAY generated animation of granular flow

Day 4: Computational Science

- What/Why/How?

- Physics Based Gaming

- Computer Aided Engineering

- Computer Game: Car Racing

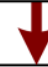

Day 5: Applications

- Feedback and evaluation

- Computer Games: Race Day

- ADAMS HMMWV model, passenger car, tracked vehicle
Applied Mathematics, Computer Science, CAD, and video gaming. The instructional segment is complemented with several other activities: university lab visits, round table discussion with current minority engineering students, meeting with Industry representatives, meeting with University of Wisconsin staff to discuss admissions and college preparation, three-on-three basketball tournaments, and live outdoor music at the Student Memorial Union.

In an effort to increase the interest and recruitment of the next generation of experts in the pursuit of space- or aerospace-related science, the ProCSI program incorporated a space module in 2010. The space module focused on simulations in low gravity, such as modeling the Mars Rover navigating through fine Martian regolith or a sieve that operates on the Moon. Additionally, ProCSI had Dr. Matt Melis, of the NASA Glenn Research Center, visit and talk to students to encourage space-related pursuits. During ProCSI 2009 and 2010, Dr. Melis presented his work on the investigation into the Columbia Shuttle Disaster. For the ProCSI 2011 session, Dr. Abhi Jain, a scientist from the NASA Jet Propulsion Lab will come to present his work on the use of simulations and computer modeling in space exploration.

In terms of impact assessment, the web-based Student Assessment of Learning Gains Instrument (SALGI), developed by the National Institute for Science Education (NISE) College Level One Team under NSF support at the University of Wisconsin, will be used for outcome control and implementation of a continuous improvement process, which also draws on exit interviews with the participants. All 2008 ProCSI alumni went on to college in Fall 2009 at University of Wisconsin-Madison, University of WisconsinMilwaukee, DePaul, Southern Illinois UniversityEdwardsville, and Howard University. Partial ProCSI funding for 2008 was secured through NSF project CMMI- 
0700191, and for 2009 to 2013 through NSF project CMMI-0840442. Additional funding was provided by an industry partner (BAE Systems).

The 2011 goal of teacher training has been, and will continue to be achieved through graduate student members of the SBEL lab. They recruit, organize and teach a majority of the seminars for the ProCSI event. This teaching is new to all of these students and provides a valuable learning experience for both the participants of ProCSI and the graduate student teachers. 